\title{
NOVEDADES DE PRODUCTOS Y MERCADOS EN LAS EXPORTACIONES DOMINICANAS: ¿HACIA UN NUEVO PATRÓN DE COMERCIO?
}

New products and markets in Dominican exports: Towards a new pattern of trade?

\section{Pável Isa Contreras* Bymairy de León ${ }^{* *}$ Virginia Melo ${ }^{* * *}$}

Resumen: Este artículo hace una evaluación de la reestructuración que han sufrido las exportaciones de bienes de la República Dominicana desde mediados de la década de 2000 en adelante, y busca identificar patrones de cambio. Se muestra que el grueso de las exportaciones ha retrocedido como resultado de la reducción en las exportaciones de confecciones textiles a Estados Unidos, y que las exportaciones de manufacturas hacia Haití han contribuido significativamente a contrarrestar esa caída. Sin embargo, advierte que no emerge un patrón claro, y esa reestructuración no ha sido esencialmente la consecuencia de una estrategia de conquista de mercados alternativos y de promoción de nuevos productos sino un resultado espontáneo. Concluye con algunas interrogantes sobre la sostenibilidad del crecimiento de las nuevas exportaciones y el rol que puede jugar la política pública.

Palabras clave: exportaciones, mercados, productos, República Dominicana.

Profesor investigador del Instituto Tecnológico de Santo Domingo (INTEC), Área de Negocios. Email: pavel.isa@intec.edu.do

** Economista (Summa Cum Laude), egresada del Instituto Tecnológico de Santo Domingo (INTEC).

** Egresada de la carrera de Economía del Instituto Tecnológico de Santo Domingo (INTEC). 


\begin{abstract}
This article assesses the restructuring that exports of goods of the Dominican Republic have experienced since the mid2000 s onwards, and seeks to identify patterns of change. It shows that the bulk of exports has fallen as a result of the reduction in exports of textile apparel to the United States, and manufactured exports to Haiti have contributed significantly to offset that decline. Note however that no clear pattern emerges, and this restructuring has not been essentially the result of a strategy of conquest of alternative markets or due export promotion but a spontaneous result. It concludes with some questions about the sustainability of growth in new exports and the role that public policy can play.
\end{abstract}

Keywords: exports, markets, products, Dominican Republic.

\title{
1. Introducción
}

Las exportaciones dominicanas de bienes han sufrido un significativo cambio a lo largo de la última década. Aunque se han mostrado poco dinámicas, alcanzando en 2012, en términos reales per cápita, apenas un $11 \%$ más del valor observado en 2000 , se han reestructurado de manera notable. Las exportaciones de confecciones textiles en general y hacia los Estados Unidos en particular redujeron su peso en las exportaciones totales mientras otras como las de productos primarios y manufacturas diversas se abrieron paso. Esto ha resultado en una diversificación de productos, pero también de mercados. ${ }^{1}$

1 Véase Isa Contreras, P. (2013): “Indicadores seleccionados del desempeño exportador de la República Dominicana: evaluación de una década”, Ciencia y Sociedad, 38(1), 83-114.

704 Ciencia y Sociedad 2014; 39(4): 703-730 
Sin embargo, queda la pregunta si esta reestructuración de productos y mercados está conformando un nuevo y definido patrón de comercio. ¿Cuáles son los productos que encabezan la lista de los de mayor crecimiento del valor exportado, más allá de "nuevas manufacturas" o de "productos primarios"? ¿A cuáles mercados se dirigen? Más aún, ¿se trata de productos prometedores o más bien de prognosis reservada? Además de las confecciones textiles, cha habido otros retrocesos significativos?

Este trabajo procura responder a estas preguntas en procura de ir actualizando el cambiante perfil exportador de República Dominicana. En la segunda sección se destacan los productos de exportación más dinámicos en la última década, tanto en términos del crecimiento porcentual del valor exportado como del cambio en el peso en las exportaciones totales. En la tercera sección se describe brevemente los mercados ganadores y perdedores para el comercio exportador dominicano. En la cuarta sección se desarrolla un análisis del dinamismo de las exportaciones en los mercados más importantes utilizando una conocida metodología de la CEPAL que las clasifica en cuatro categorías: "estrellas nacientes", "estrellas menguantes", "oportunidades perdidas" y "retiradas". La quinta sección introduce al análisis de las ventajas comparativas reveladas (VCR) para el caso dominicano. La última sección resume los hallazgos.

\section{Las nuevas exportaciones: ¿emerge algún patrón?}

La diversificación de las exportaciones dominicanas en la última década ha sido notable. Isa-Contreras (2013) muestra que el Índice Herfindhal de las exportaciones de bienes del país se redujo desde 0.15 hasta 0.04 entre 2002 y 2011, que la participación de las exportaciones de manufactureras, en especial las de confecciones textiles se redujeron, y que se abrieron paso nuevos rubros 
incluyendo otras manufacturas y productos primarios ${ }^{2}$. Sin embargo, ¿cuáles son esas exportaciones? ¿De cuáles productos se trata?

El cuadro 1 ofrece un listado de los capítulos del Sistema Armonizado (SA) en los cuales el país registró un aumento relevante del valor de las exportaciones desde 2006 hasta 2011. Para buscar identificar tendencias, se compara el crecimiento del valor absoluto de las exportaciones medias anuales durante el trienio 2009-2011 respecto al valor medio registrado en el trienio 2006-2008.

Como se evidencia, se trata de un grupo de productos diversos, los cuales incluyen manufacturas y productos primarios tales como artículos de cobre, aparatos médicos, frutas, productos plásticos y cacao y preparaciones.

Llama la atención que el capítulo que registró un incremento absoluto más elevado fue el capítulo 74 referido al cobre y productos de cobre. Una evaluación más detallada de los subcapítulos que lo componen revela que el grueso de las exportaciones de este tipo de productos es del subcapítulo 7404 referido a desperdicios y desechos de cobre. En promedio entre 2009 y 2011, las exportaciones de este tipo de productos aumentaron en US $\$ 242$ millones comparado con el período 2006-2008. El aumento en el precio de los metales y desperdicios de metal en el mundo generó un aumento de las exportaciones de chatarras y desperdicios de metal en general, e incentivó actividades ilegales de extracción de metales para fines de exportación. Por lo tanto, no se trata de una actividad manufacturera que genera valor agregado.

2 El Índice de Herfindhal es un popular indicador para medir el grado de concentración de mercados y otros. Es la suma del cuadrado de las participaciones de mercado o de productos. $\mathrm{H}=\sum\left(\mathrm{s}^{2}\right)$, donde $\mathrm{H}$ es el índice y s es la participación del producto en las exportaciones totales. Se puede expresar en porcentajes o, como acá, en cocientes, en cuyo caso, el máximo que alcanza el índice (extrema concentración) es 1. 


\section{Cuadro 1}

Exportaciones más dinámicas en República Dominicana 2006-2011

Capítulos del Sistema Armonizado (SA) cuyas exportaciones crecieron en US\$ 50 millones o más entre 2006-08 y 2009-11

\begin{tabular}{|c|l|c|}
\hline Capítulo & \multicolumn{1}{|c|}{ Descripción } & $\begin{array}{c}\text { Aumento del valor } \\
\text { de exportaciones } \\
\text { (millones US\$) } \\
\text { 2006-08 - 2009-2011 }\end{array}$ \\
\hline 74 & Cobre y artículos de cobre & 242.4 \\
\hline 90 & Aparatos médicos, ópticos, de fotografía & 235.6 \\
\hline 08 & Frutas & 230.8 \\
\hline 39 & Productos plásticos & 221.0 \\
\hline 18 & Cacao y preparaciones & 186.9 \\
\hline 30 & Productos farmacéuticos & 185.8 \\
\hline 11 & Productos de molinería (harina de trigo) & 115.3 \\
\hline 52 & Algodón y tejidos de algodón & 109.8 \\
\hline 17 & Azúcar y confecciones de azúcar & 101.0 \\
\hline 25 & Sal, sulfuros, cemento & 96.8 \\
\hline 63 & Otros artículos textiles & 65.0 \\
\hline 22 & Bebidas, bebidas alcohólicas y vinagre & 60.6 \\
\hline 21 & Preparaciones alimenticias misceláneas & 51.8 \\
\hline
\end{tabular}

Fuente: Elaborado con información de TradeMap.org

El segundo capítulo que mayor incremento registró en el valor exportado fue el capítulo 90 que corresponde a aparatos médicos, ópticos y de fotografía, en particular los capítulos 9018 (instrumentos y aparatos de medicina, cirugía, odontología o veterinaria), 9022 (aparatos de rayos x y que utilicen radiaciones) y 9031 (instrumentos y aparatos y máquinas de medida o control). Se trata estrictamente de exportaciones de un conjunto de empresas 
ubicadas en parques de zonas francas de exportación las cuales han visto incrementar su producción y exportación de numerosos productos médicos como resultado de un aumento de la demanda mundial de este tipo de productos, de decisiones corporativas a nivel global y de algunas ventajas que ofrece el país, en particular en algunos parques industriales especializados. La producción tiende a ser intensiva en capital y conocimiento. Como resultado, este se ha convertido en el principal rubro de exportación del país en términos del valor exportado. Entre 2009 y 2011, estas exportaciones se incrementaron en US $\$ 235.6$ millones comparado con el promedio verificado entre 2006 y 2008.

Las frutas (capítulo 08) es el tercer grupo de productos que mayor incremento registró en el valor exportado en 2009-2011 comparado con el período 2006-2008. El incremento fue de poco menos de US $\$ 231$ millones e incluye cocos, bananos, aguacates, mangos, cítricos, melones, sandías, papayas y otros productos frescos.

A estos tres capítulos le siguen productos plásticos, cacao y preparaciones, y productos farmacéuticos, con incrementos de US\$ 221 millones, US\$ 187 millones y US\$ 186 millones, respectivamente. En el caso de los productos farmacéuticos, estos son elaborados en las zonas francas de exportación y son productos como gasas, vendas y artículos de algodón para suturas y vendajes, y preparaciones y artículos para obturación dental y otros.

Otros productos destacados por el incremento en el valor nominal de las exportaciones son productos de molinería (en particular harina de trigo), tejidos de algodón, azúcar, cemento, otros productos textiles, bebidas y preparaciones alimenticias.

Por otra parte, no solo el cambio en el valor nominal de las exportaciones es relevante sino también el cambio en su participación en las exportaciones totales. Cuando el dinamismo de nuevos productos exportados se mide por este indicador, los que más se 
destacan son los aparatos médicos con un aumento en su participación de casi $4 \%$, los productos plásticos con un aumento de $2 \%$, las frutas con un aumento de casi $2 \%$, el cacao y preparaciones y tejidos de algodón con $1.7 \%$ cada uno, el cobre y desperdicios de cobre con 1.6\%, los productos farmacéuticos con 1.4\%, el azúcar y confecciones con $1.1 \%$ y el tabaco y manufacturas con $1 \%$. En ese sentido, dos nuevos grupos de productos aparecen como destacados: el azúcar y los productos de tabaco.

Como es evidente, por cualquier indicador que se les mida, la diversidad es una característica muy destacada de los rubros de exportaciones del país. Entre ellos aparecen productos elaborados en las zonas francas distintos de los textiles tales como aparatos médicos y productos farmacéuticos, y productos primarios y manufacturas producidas fuera de las zonas francas.

En ese sentido, un análisis de la composición de las exportaciones de los trece capítulos que registraron aumentos de más de US\$ 50 millones en el valor exportado entre 2006-2008 y 2009-2011, apunta a que no emerge un patrón de productos y actividades claramente identificable. Como se advierte en el cuadro 2, el 12.7\% del aumento de esos 13 capítulos es explicado por desperdicios de metal, un $31 \%$ por productos de manufactura nacional, poco menos de $29 \%$ por nuevas exportaciones de zonas francas, y un $27 \%$ por productos primarios. Lo anterior podría también suponer que en el proceso de reestructuración de las exportaciones, las políticas explícitas de comercio exterior han tenido poco que ver con el proceso y que probablemente se ha tratado de un proceso relativamente autónomo y espontáneo. 


\section{Cuadro 2}

Composición de las exportaciones de los 13 capítulos que registraron aumentos de US\$50 millones o más en exportaciones entre 2006-2008 y 2009-2011

\begin{tabular}{|l|r|l|}
\hline Desperdicios de metal & 242.4 & $12.7 \%$ \\
Productos elaborados en zonas francas & 596.2 & $31.3 \%$ \\
Productos de industria manufacturera local & 545.5 & $28.7 \%$ \\
Productos primarios & 518.7 & $27.3 \%$ \\
\hline \multicolumn{1}{|c|}{ Total } & $\mathbf{1 , 9 0 2 . 8}$ & $\mathbf{1 0 0 . 0 \%}$ \\
\hline
\end{tabular}

Fuente: Elaborado con información de TradeMap.org

\section{Nuevos mercados, nuevas oportunidades}

Hasta ahora el análisis se ha concentrado en las exportaciones por grupo de productos. Sin embargo, merece atención la reestructuración de las exportaciones por mercados de destino. Isa Contreras (2013) apuntó que de la misma forma en que se verificó una reducción del grado de concentración del valor de las exportaciones en términos de productos, también se verificó una diversificación de destinos. En Indice de Herfindhal de concentración por destinos se redujo desde 0.628 en 2002 hasta 0.356 en 2010.

Pero ¿cuáles son los nuevos destinos? ¿Cuáles países se han destacado como destinos de exportación en años recientes? ¿Cuáles países han perdido peso como destino de exportaciones de bienes?

Una simple descripción de la composición de las exportaciones por mercados de destino entre 2006 y 2011 permite obtener tres conclusiones muy evidentes:

1) El mercado de los Estados Unidos retrocedió en su participación en las exportaciones totales de bienes; 
2) El mercado de Haití ganó significativa participación; y

3) El resto de los mercados, de menor importancia, no revelaron cambios significativos.

En efecto, la participación del mercado de los Estados Unidos cayó desde $67 \%$ en 2006 hasta menos de 55\% en 2011. Se trata de una reducción vinculada a la caída de las exportaciones de confecciones textiles hacia ese país como resultado del cambio en las reglas del comercio internacional de textiles. Por su parte, como se ve en el gráfico 1, el mercado de Haití más que triplicó su participación en las exportaciones totales de bienes en ese período al pasar de $5 \%$ a $16.6 \%$. En contraste, las participaciones de las exportaciones hacia los 27 países de la Unión Europea (UE), hacia los 5 países de Centroamérica (CA) y hacia otros destinos apenas se modificaron. Las destinadas hacia los países de la UE se incrementaron desde US $\$ 417$ millones hasta US $\$ 492$ millones y su peso creció apenas de $6.9 \%$ a $8 \%$. Las dirigidas hacia los países de CA casi se cuadruplicaron pero desde niveles muy bajos. Pasaron de US\$ 34 millones a US\$ 129 millones, incrementando su participación desde $0.6 \%$ en 2006 hasta $2.1 \%$ en 2011 . Vale indicar que el valor registrado en 2011 es significativamente superior al observado en el promedio del período 2009-2011 que fue de US\$ 82 millones. Por último, otros destinos de exportación redujeron su peso desde cerca de $21 \%$ en 2006 hasta cerca de $19 \%$ en 2011. 


\section{Gráfico 1}

Composición de las exportaciones dominicanas por grandes mercados de destino 2006-2011

(\% de exportaciones totales)

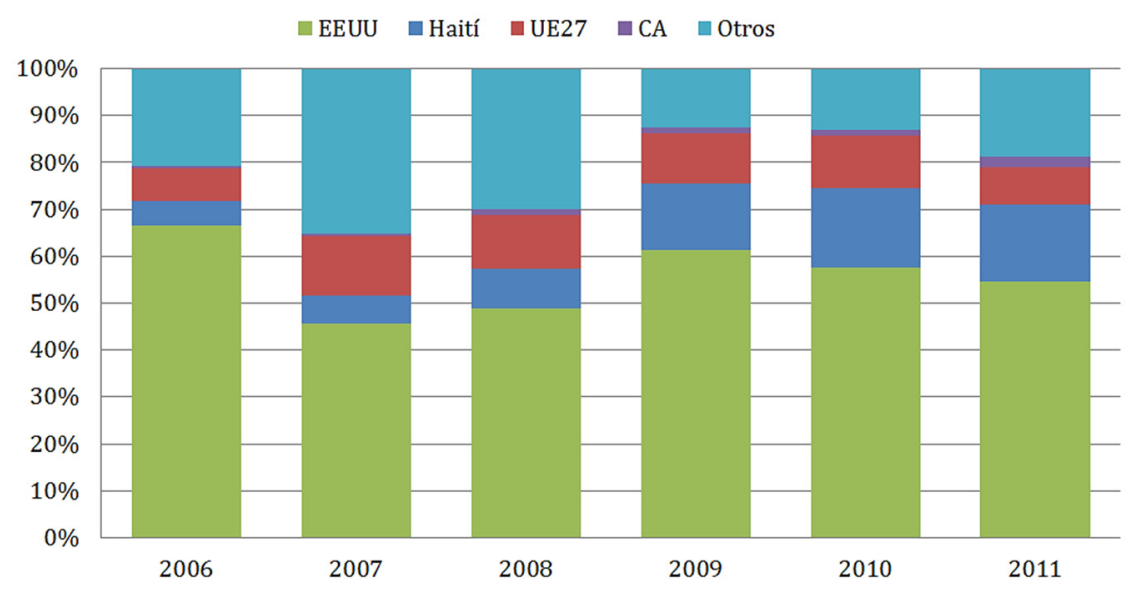

De lo anterior se evidencia que en términos de mercado de destino, la reducción notable de las exportaciones hacia Estados Unidos y el incremento de estas hacia Haití es la novedad en el período. Más aún, una comparación del cambio absoluto en el valor de las exportaciones hacia ambos mercados entre 2006 y 2001 sugiere que la reducción de las exportaciones hacia Estados Unidos fue compensada por un aumento de las exportaciones hacia Haití, evitando una caída significativa del valor total exportado. En efecto, mientras entre 2006 y 2011 las exportaciones hacia Estados Unidos cayeron en poco menos de US\$ 721 millones, las dirigidas al mercado haitiano en ese mismo período aumentaron en US\$702 millones (véase el gráfico 2). El resto de los destinos de exportación apenas vieron modificarse sus valores nominales en ese período. 


\section{Gráfico 2}

Cambio absoluto en el valor de las exportaciones dominicanas

2006-2011 por país de destino

(en millones de US\$)

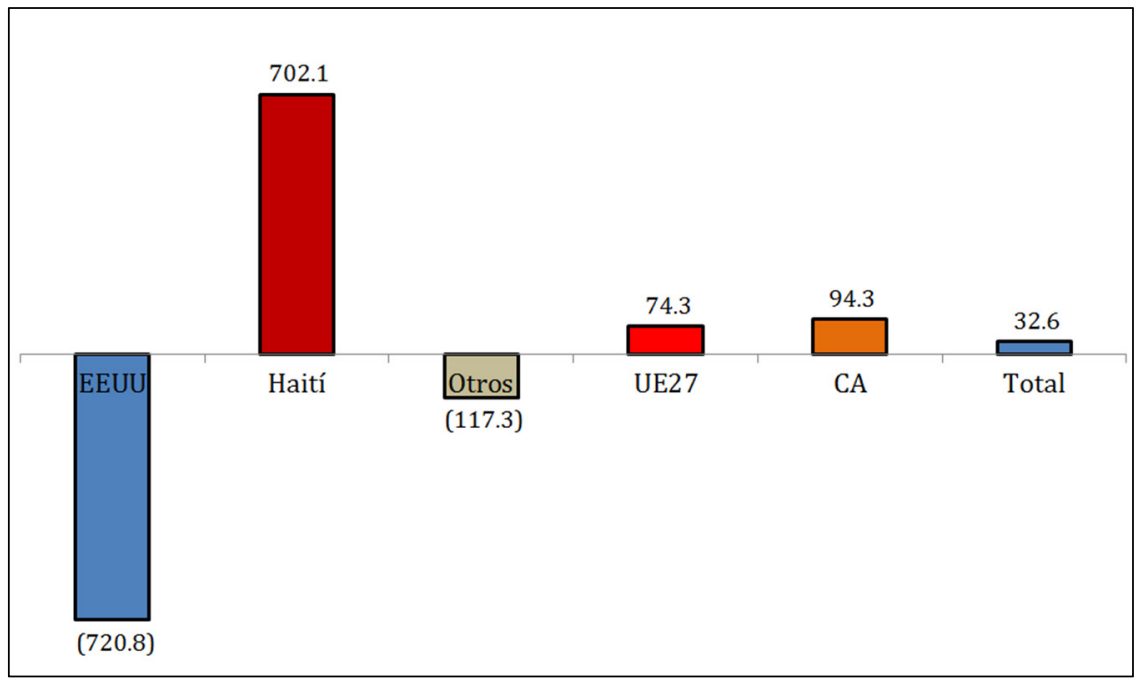

Estas cifras destacan, por lo tanto, la importancia que ha adquirido el mercado de Haití para el comercio exterior dominicano y el rol de amortiguamiento de la reducción de las exportaciones hacia Estados Unidos que ha jugado ese mercado.

A partir de la evidencia de que ha ocurrido una significativa diversificación de las exportaciones de bienes, y una reestructuración de los mercados de exportación hacia Haití, cabe preguntarse si emerge algún tipo de patrón en términos de productos y mercados. De manera más precisa: ¿cuáles exportaciones han caído y hacia cuáles mercados? ¿Cuáles han crecido y hacia cuáles mercados? ¿Las caídas se limitan a las confecciones textiles hacia Estados Unidos? ¿Han emergido nuevas exportaciones hacia ese país? ¿Cuáles? ¿Cuáles son los productos que han incrementado sus ventas en Haití? ¿Se han verificado reestructuraciones significativas en otros mercados de exportación? 
Un análisis más detallado de la dinámica de las exportaciones dominicanas hacia Estados Unidos entre 2006 y 2011 revela que la caída en el valor total de las exportaciones hacia ese país fue una consecuencia - casi una exclusiva- de una caída en las exportaciones de prendas de vestir no de punto. De 13 capítulos del SA analizados, los cuales individualmente representaron un $1 \% \mathrm{o}$ más del valor total de las exportaciones hacia ese mercado en ese período, se advierte que seis de ellos registraron caídas, mientras que siete registraron incrementos. Sin embargo, la caída en el capítulo 62 (Prendas y complementos de vestir, excepto los de punto) fue de US\$1,018.7 millones, fue por mucho el más destacado movimiento. El valor de la reducción en ese capítulo fue mayor al de la reducción en el valor de las exportaciones.

Como se advierte en el gráfico 3, otros capítulos que registraron caídas fueron hierro y acero (72), aparatos eléctricos y sus partes (85), prendas de tejido de punto (61), joyas (71) y artículos de papel y cartón (48). Sin embargo, estas últimas tuvieron un peso mucho menor a las de confecciones no de punto. Mientras, los que experimentaron incrementos fueron, en orden descendente, instrumentos ópticos y fotográficos (capítulo 90), productos farmacéuticos (30), calzados (64), tabaco (24), plásticos (39), cacao (18) y azúcar (17). 


\section{Gráfico 3}

Cambio absoluto en el valor de las exportaciones dominicanas a Estados Unidos 2006-2011 por grupo de productos seleccionados (millones de US\$)

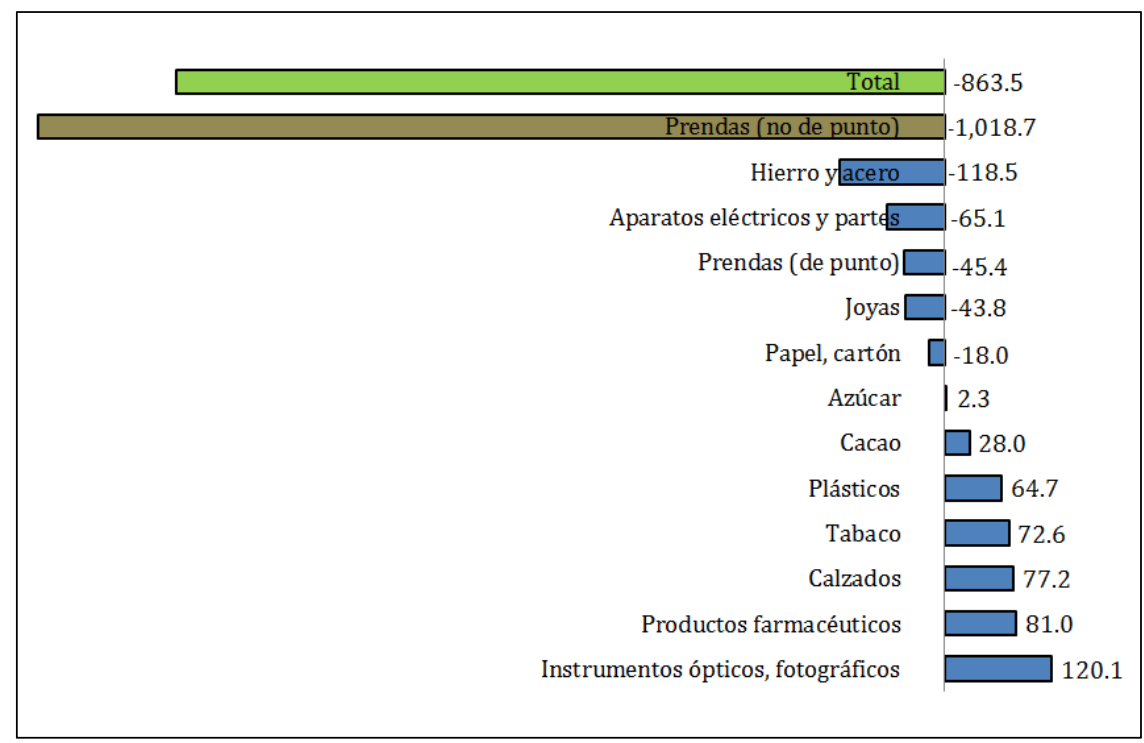

Por su parte, un análisis similar para el caso de las exportaciones hacia Haití revela un incremento de bas relativamente amplia. Igual que en el caso de Estados Unidos, se seleccionaron aquellos capítulos que durante el período 2006-2011 explicaron no menos del $1 \%$ del valor total exportado hacia ese mercado. El aumento del valor total exportado de esos capítulos fue de US\$ 602 millones. Como se aprecia en el gráfico 4, las exportaciones que mostraron más dinamismo fueron tejidos de algodón (capítulo 52), los productos de molinería (11), los productos de hierro y acero (72), los productos plásticos (39), y el cemento (25). Como se advierte, todos ellos fueron productos o grupos de productos manufacturados. 


\section{Gráfico 4}

Cambio absoluto en el valor de las exportaciones dominicanas hacia Haití 2006-2011 por grupo de productos seleccionados (millones de US\$)

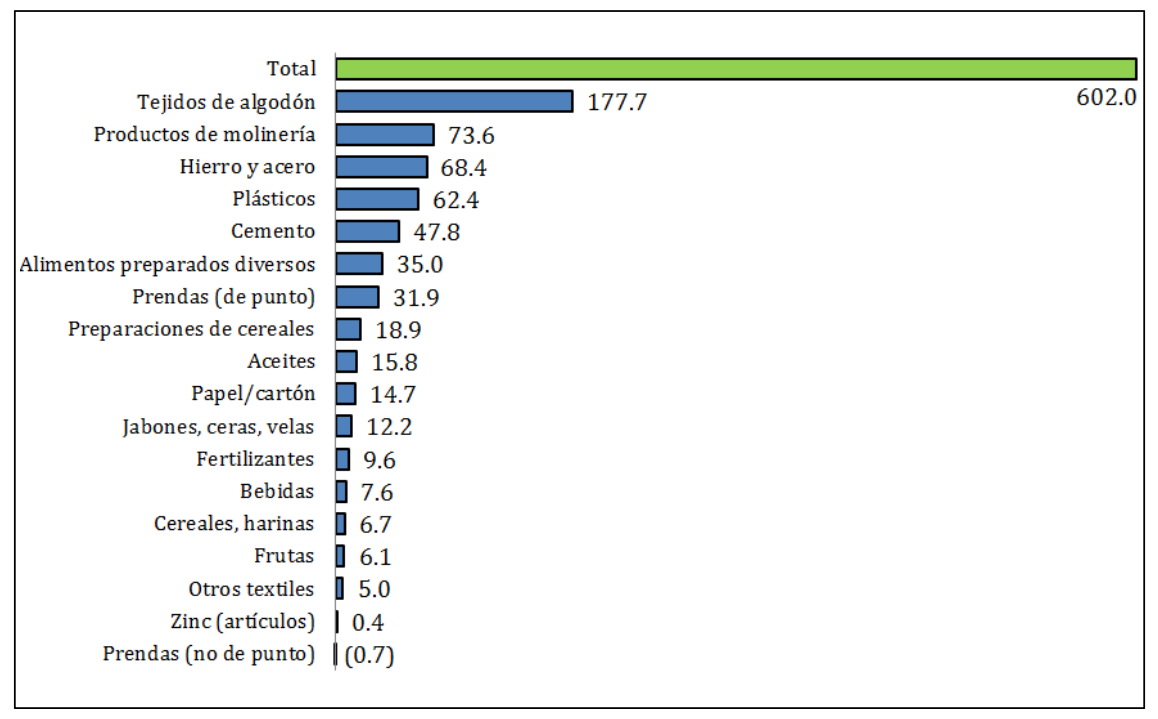

La siguiente sección recurre a una metodología desarrollada por la CEPAL para el análisis del desempeño exportador, en particular para evaluar el dinamismo exportador de grupos de productos específicos, tanto en el mercado internacional global como en mercados externos específicos.

\section{Las estrellas del comercio exportador dominicano}

A inicios de la década pasada, la CEPAL desarrolló una ingeniosa pero simple metodología que procura clasificar los rubros de exportación respecto a dos desempeños durante un período de tiempo determinado: el cambio en la participación de estos en el comercio mundial, y el cambio del comercio mundial de éstos en 
el comercio mundial total. ${ }^{3}$ A partir de esos dos criterios, clasifica los productos o grupos de productos en cuatro categorías:

- Estrellas nacientes: son aquellas exportaciones que aumentaron su participación en las exportaciones totales y que a la vez creció el comercio mundial de ellas respecto al total del comercio. Se refiere entonces a productos prometedores no solo por su buen desempeño en las exportaciones del país sino por su dinamismo en el mercado mundial.

- Estrellas menguantes: son aquellas que aumentaron su participación en las exportaciones totales pero que la participación del comercio mundial de ese bien en el comercio internacional total declinó. En otras palabras, se trata de productos con buen desempeño en el país pero en declive en el comercio mundial.

- Oportunidades perdidas: son las que declinaron en su participación en las exportaciones totales pero, en contraste, las exportaciones mundiales vieron incrementar su peso en las exportaciones mundiales totales. Como su nombre lo indica, se trató de una oportunidad no aprovechada.

- Retiradas: son las que perdieron participación en las exportaciones totales y a la vez, el comercio mundial de ese producto declinó como proporción del comercio total.

En términos formales, el indicador es el siguiente:

$$
I=X_{i}^{j} / \sum X_{m}^{j} / \sum X_{m}^{j} / \sum X^{m}
$$

En donde el numerador es la cuota de mercado del país en el comercio mundial del producto, y el denominador es la participación del comercio mundial del producto en el comercio mundial total. $X_{i}^{j}$ es la exportación del país $i$ del bien $j, \sum X_{m}^{j}$ es

3 Para una explicación y una aplicación de la metodología véase el trabajo de Dussel (2001). 
la suma de todas las exportaciones de ese producto ( () en el mundo, y $\sum X^{m}$ es la suma del comercio mundial de todos los productos. Si el numerador y el denominador son positivos, se trata de una "estrella naciente"; si el numerador es positivo y el denominador es negativo, se trata de una "estrella menguante"; si es al revés, es una "oportunidad perdida"; y si ambos, numerador y denominador, son negativos, es una "retirada".

Una elevada participación de "estrellas nacientes" en las exportaciones totales apunta hacia un aprovechamiento de oportunidades que ofrece el mercado internacional, en contraste con el caso en que la concentración de productos se dé en "oportunidades perdidas".

En el caso de que exista una alta participación de "estrellas menguantes", la lectura debe ser que aunque el país haya tenido buen desempeño en estas actividades, en la medida en que se trata de productos "en declive" las políticas y las empresas deberían considerar medidas precautorias para redireccionar el comercio y la oferta exportable, a menos que la apuesta sea por ocupar espacios que otros países abandonan en esos mercados.

Por último, las retiradas indican, siguiendo el término, un retroceso exportador en productos que están menguando en el comercio internacional. Aunque en principio se interpretan como desempeños negativos en el marco de un entorno comercial desfavorable, los cuales las políticas y las decisiones empresariales no lograron evitar, hay que reconocer una lectura alternativa: que las retiradas forman parte de procesos de reestructuración del comercio en el marco de declives de algunos productos en el comercio mundial.

Por lo anterior, hay que indicar que de esta clasificación no se derivan claras pautas normativas para el comercio, especialmente en el marco de un proceso de reestructuración de las exportaciones. Estos procesos pueden tomar diversos caminos. Uno de ellos es una primera fase que esté marcada por un alto peso de "retiradas", para luego dar paso a un aumento de la participación de "estrellas 
nacientes". Otro es que la primera fase sea de alta participación de "estrellas menguantes" que terminen siendo "retiradas", para eventualmente abrir paso a numerosas "estrellas nacientes". Un tercer camino es que, como resultado de acciones de política y de reacción empresarial oportuna, se dé el paso rápido desde "estrellas menguantes" a "estrellas nacientes".

A pesar de eso, en principio, un elevado peso de "retiradas" o de "oportunidades perdidas" apunta hacia un desempeño exportador poco dinámico o en deterioro, y un alto peso de "estrellas menguantes" a restricciones en el futuro inmediato. Por el contrario, como se indicó antes, una alta participación de "estrellas nacientes" sugiere un aprovechamiento de oportunidades en los mercados externos.

En el caso de las exportaciones dominicanas, se realizó un análisis para el período 2006-2011 a partir de una selección de los capítulos del SA cuyas exportaciones explicaran al menos un $0.5 \%$ del total de las exportaciones para ese período. El ejercicio arrojó los siguientes resultados, los cuales se presentan en el cuadro 3:

- El 53.5\% de todas las exportaciones fueron "retiradas". Eso significa que más de la mitad de las exportaciones del país retrocedieron y se trata de productos "perdedores" en el mercado mundial. No sorprende que entre las retiradas destaquen artículos y accesorios de tejidos y debido al cambio en las reglas del comercio mundial de textiles que afectó negativamente las exportaciones de estos productos hacia Estados Unidos, pero además, calzados, hierro y acero, y otros.

- El 19.1\% fueron "oportunidades perdidas", es decir, productos cuya participación en las exportaciones totales cayó, a pesar de que fueron productos dinámicos en el mercado internacional. Entre ellas se encuentran el azúcar, el tabaco, bebidas alcohólicas, y preparaciones alimenticias diversas como sopas y salsas. 
- Las retiradas y las oportunidades perdidas explican más del 72\% de las exportaciones dominicanas del período 2006-2011.

- Solo el 14.5\% fueron "estrellas nacientes". Consistieron en vegetales, frutas, cacao y productos de belleza como shampoo y enjuagues.

- Menos del 13\% fueron estrellas menguantes. Entre ellas se encuentran el cemento, los artículos de plásticos y tejidos de algodón.

\section{Cuadro 3}

Clasificación de exportaciones de los 25 capítulos que representaron $0.5 \%$ o más de las exportaciones para el período 2006-2011 por el "método CEPAL"

\begin{tabular}{|c|c|c|}
\hline Categorías & $\begin{array}{c}\text { Porcentaje de } \\
\text { exportaciones }\end{array}$ & $\begin{array}{c}\text { Número de } \\
\text { capítulos }\end{array}$ \\
\hline Estrellas menguantes & $12.9 \%$ & 6 \\
\hline Estrellas nacientes & $14.5 \%$ & 7 \\
\hline Oportunidades perdidas & $19.1 \%$ & 5 \\
\hline Retiradas & $53.5 \%$ & 7 \\
\hline Total general & $100.0 \%$ & 25 \\
\hline
\end{tabular}

Fuente: Elaborado con información de TradeMap.org

No obstante, el análisis y clasificación de las exportaciones también se extendió al caso de los tres mercados de exportación individualmente más importantes para el país por separado: Estados Unidos, Haití y los países de la Unión Europea.

En el caso de las exportaciones hacia Estados Unidos, como puede verse en el cuadro 4 , el $42 \%$ fue oportunidades perdidas, $y$ el $27.5 \%$ fue retiradas, para un total combinado de más de $70 \%$. El $23.4 \%$ fue estrellas menguantes, y apenas el $7.1 \%$ fue estrellas nacientes. 
Entre las retiradas destacan las prendas de vestir, el hierro y el acero. En las oportunidades perdidas se advierte el azúcar (vinculado a las cuotas del comercio de azúcar del DR-CAFTA) y algunas exportaciones de zonas francas como maquinaria y aparatos eléctricos, así como instrumentos ópticos y fotografía. El tabaco y los productos plásticos se encuentran entre las estrellas menguantes, así como calzados y productos relacionados. Por su parte, las estrellas nacientes se limitaron a cacao y productos farmacéuticos, estos últimos elaborados en zonas francas.

\section{Cuadro 4}

Clasificación de exportaciones dominicanas hacia Estados Unidos de los capítulos que representaron $0.5 \%$ o más de las exportaciones para el período 2006-2011 por el "método CEPAL"

\begin{tabular}{|c|c|}
\hline Categorías & $\begin{array}{c}\text { Porcentaje } \\
\text { de exportaciones }\end{array}$ \\
\hline Estrellas menguantes & $23.4 \%$ \\
\hline Estrellas nacientes & $7.1 \%$ \\
\hline Oportunidades perdidas & $42.0 \%$ \\
\hline Retiradas & $27.5 \%$ \\
\hline Total general & $100.0 \%$ \\
\hline
\end{tabular}

Fuente: Elaborado con información de TradeMap.org

En contraste, el dinamismo de las exportaciones hacia Haití es notable y contrasta con el comportamiento de las dirigidas al resto del mundo. Como se advierte en el cuadro 5, el 70\% de ellas fueron "estrellas nacientes", y el 20.6\% eran "estrellas menguantes". Las "oportunidades perdidas" y las "retiradas" no alcanzaron un 10\% del total. 
Entre las "estrellas nacientes" destacan los tejidos de algodón (comercio de zonas francas a zonas francas), los productos plásticos, las preparaciones alimenticias diversas como sopas y salsas, el cemento, las pastas alimenticias, los aceites comestibles y los fertilizantes. De esta forma, las exportaciones hacia Haití están dominadas por las manufacturas, tanto de la industria nacional como de las zonas francas de textiles.

\section{Cuadro 5}

Clasificación de exportaciones dominicanas hacia Haití de los capítulos que representaron $0.5 \%$ o más de las exportaciones para el período 2006-2011 por el "método CEPAL"

\begin{tabular}{|c|c|}
\hline Categorías & $\begin{array}{c}\text { Porcentaje } \\
\text { de exportaciones }\end{array}$ \\
\hline Estrellas menguantes & $20.6 \%$ \\
\hline Estrellas nacientes & $70.0 \%$ \\
\hline Oportunidades perdidas & $3.6 \%$ \\
\hline Retiradas & $5.8 \%$ \\
\hline Total general & $100.0 \%$ \\
\hline
\end{tabular}

Fuente: Elaborado con información de TradeMap.org

Con respecto a las exportaciones hacia los países de la Unión Europea, la clasificación es mixta. Aunque menos de un $42 \%$ es "estrellas nacientes", un 30\% es "retiradas". Sin embargo, su peso en las exportaciones totales sigue siendo limitado. 


\section{Ventaja Comparativa Revelada (VCR): una introducción para el caso dominicano}

El Índice de la Ventaja Comparativa Revelada o VCR es un indicador sencillo propuesto por Balassa (1965) cuya finalidad es identificar aquellos productos y grupos de productos en los que un país tiene ventaja comparativa. Este indicador supone que si el país tiene un relativamente elevado nivel de especialización en ese producto en el comercio internacional, es porque tiene ventaja comparativa en él. En ese sentido, el indicador se abstrae de factores como las políticas para explicar el nivel de especialización.

El Índice de VCR es el resultado del cociente de dividir la participación del producto o de los productos en cuestión en el valor total exportador por el país, entre la participación las exportaciones de ese producto en el mundo en las exportaciones mundiales totales.

$$
V C R=\left(X_{i}^{j} / X_{j}\right) /\left(X_{m}^{i} / X^{m}\right)
$$

$X_{i}^{j}$ es las exportaciones del bien $i$ del país $j, X_{j}$ es el valor de las exportaciones totales de $j, X_{m}^{i}$ es las exportaciones del bien $i$ de todo el mundo y $X^{m}$ es las exportaciones mundiales agregadas. Si este cociente es superior a 1 para un bien específico, se dice que ese país revela tener ventajas comparativas en ese bien. Si el cociente es inferior a 1 es lo contrario.

Para este trabajo se realizó un ejercicio sencillo de estimación de las VCR para el período 2006-2011, y para los subperíodos 20062008 y 2009-2011 con el objetivo de identificar cambios a lo largo del tiempo en la especialización internacional del país.

El cuadro 6 ofrece los resultados y considerando la discusión de las secciones anteriores, no aparecen muchas sorpresas. Los productos en los que el país aparece relativamente especializado en el período 2006-2011 (32 capítulos del Sistema Armonizado) son aquellos que tienen un relativamente alto peso en la canasta de 
exportación. A juzgar por el Índice VCR, República Dominicana está altamente especializada en la exportación de tabaco y manufacturas, tejidos de algodón (vinculadas a las exportaciones de empresas de zonas francas hacia Haití descritas arriba), cacao, prendas de vestir no tejidas (zonas francas), azúcar y productos de molinería. También, aunque en menor medida en calzados (zonas francas), prendas de vestir tejidas (zonas francas), frutas, hierro, cemento (estos dos últimos especialmente hacia Haitî) y aparatos médicos, ópticos y fotográficos (zonas francas).

En conjunto, todos los productos con un VCR $>1$ explicaron el $81.2 \%$ de las exportaciones del país en ese período. Las exportaciones de hierro y metales (varillas), aparatos médicos y ópticos (zonas francas) y prendas de vestir no tejidas, fueron las de mayor peso en las exportaciones totales.

\section{Cuadro 6}

Índice de Ventaja Comparativa Revelada

en los capítulos del Sistema Armonizado con VCR>1 2006-2011

\begin{tabular}{|l|c|c|c|c|}
\hline \multirow{2}{*}{\multicolumn{1}{c|}{ Capítulos SA }} & \multicolumn{3}{c|}{ Índice de VCR } & $\begin{array}{c}\% \\
\text { Exportaciones } \\
\text { 2006-2011 }\end{array}$ \\
\cline { 2 - 5 } & 2006-2011 & 2006-2008 & 2009-2011 & 2.4 \\
\hline Vegetales y raíces & 2.4 & 2.9 & $0.8 \%$ \\
\hline Frutas y nueces & 4.8 & 3.4 & 6.5 & $2.5 \%$ \\
\hline Café y te & 1.5 & 1.3 & 1.6 & $0.3 \%$ \\
\hline Productos de molinería & 7.4 & 3.9 & 11.4 & $0.7 \%$ \\
\hline Gomas, resinas, extractos & 2.5 & 1.2 & 3.9 & $0.1 \%$ \\
\hline Productos vegetales & 2.1 & 1.1 & 3.2 & $0.0 \%$ \\
\hline $\begin{array}{l}\text { Azúcar y confecciones } \\
\text { de azúcar }\end{array}$ & 8.1 & 7.2 & 9.3 & $2.1 \%$ \\
\hline Cacao y sus preparaciones & 10.4 & 8.2 & 13.1 & $2.4 \%$ \\
\hline Cereales, harinas & 1.9 & 1.6 & 2.1 & $0.5 \%$ \\
\hline Preparaciones alimenticias & 1.5 & 1.1 & 2.0 & $0.5 \%$ \\
\hline
\end{tabular}


Novedades de productos y mercados en las exportaciones dominicanas: ¿hacia un nuevo patrón de comercio?

\begin{tabular}{|c|c|c|c|c|}
\hline \multirow{2}{*}{ Capítulos SA } & \multicolumn{3}{|c|}{ Índice de VCR } & \multirow{2}{*}{\begin{tabular}{|c}
$\%$ \\
Exportaciones \\
$2006-2011$
\end{tabular}} \\
\hline & 2006-2011 & 2006-2008 & 2009-2011 & \\
\hline $\begin{array}{l}\text { Productos comestibles } \\
\text { misceláneos }\end{array}$ & 4.3 & 3.6 & 5.0 & $1.3 \%$ \\
\hline Bebidas & 3.2 & 2.6 & 3.9 & $1.9 \%$ \\
\hline $\begin{array}{l}\text { Tabaco y manufacturas } \\
\text { de tabaco }\end{array}$ & 22.9 & 22.8 & 23.6 & $5.7 \%$ \\
\hline Cemento & 3.8 & 2.5 & 5.6 & $1.2 \%$ \\
\hline Fertilizantes & 1.3 & 1.0 & 1.7 & $0.5 \%$ \\
\hline $\begin{array}{l}\text { Perfumes, cosméticos, } \\
\text { esencias }\end{array}$ & 1.2 & 1.0 & 1.5 & $0.7 \%$ \\
\hline Jabones, lubricantes, ceras & 0.9 & 0.6 & 1.3 & $0.3 \%$ \\
\hline Productos plásticos & 1.3 & 1.0 & 1.7 & $4.0 \%$ \\
\hline Cueros y pieles & 0.6 & 0.3 & 1.1 & $0.1 \%$ \\
\hline Papel y cartón & 2.1 & 2.0 & 2.4 & $2.5 \%$ \\
\hline Productos de algodón & 12.6 & 10.5 & 15.1 & $4.3 \%$ \\
\hline Tejidos especiales & 2.0 & 1.2 & 3.2 & $0.1 \%$ \\
\hline Prendas de vestir, tejidas & 4.0 & 4.0 & 4.1 & $4.4 \%$ \\
\hline $\begin{array}{l}\text { Prendas de vestir, no } \\
\text { tejidas }\end{array}$ & 8.9 & 11.4 & 5.6 & $10.4 \%$ \\
\hline Otros materiales textiles & 1.7 & 0.9 & 2.5 & $0.5 \%$ \\
\hline Calzados y sus partes & 5.6 & 5.3 & 5.9 & $3.6 \%$ \\
\hline Sombreros y sus partes & 3.0 & 3.4 & 2.5 & $0.1 \%$ \\
\hline Joyas & 3.1 & 4.5 & 1.8 & $6.8 \%$ \\
\hline Hierro y metales & 3.9 & 4.8 & 2.3 & $10.9 \%$ \\
\hline $\begin{array}{l}\text { Cobre y desperdicios de } \\
\text { cobre }\end{array}$ & 0.8 & 0.1 & 1.8 & $0.8 \%$ \\
\hline Zinc y artículos de zinc & 2.1 & 1.7 & 2.8 & $0.2 \%$ \\
\hline Aparatos médicos, ópticos & 3.7 & 3.2 & 4.4 & $10.9 \%$ \\
\hline Total & n.a. & n.a. & n.a. & $81.2 \%$ \\
\hline
\end{tabular}

Fuente: Elaborado con información de TradeMap.org 
Como se indicó, el ejercicio también se realizó para los subperíodos 2006-2008 y 2009-2011 a fin de identificar cambios en el tiempo. Los cambios positivos más intensos, es decir, donde se advierten un incremento significativo en el índice de VCR fueron en las exportaciones de frutas y nueces, productos de molinería, gomas y resinas, productos vegetales, cacao, comestibles misceláneos y cemento. Los cambios negativos más intensos se advierten en las exportaciones de prendas de vestir no tejidas, joyas y hierro y metales.

\section{Conclusiones y reflexiones finales}

En síntesis, el grueso de las exportaciones dominicanas de los últimos años ha retrocedido. En su mayoría se trata de exportaciones en declive en los mercados internacionales, aunque también hay un porcentaje importante de oportunidades perdidas. Además, los retrocesos han sido abrumadoramente dominados por las confecciones textiles y por exportaciones hacia los Estados Unidos.

En ese contexto, el mercado de Haití se ha constituido en la tabla de salvación que ha evitado una debacle exportadora, logrando compensar la caída de las ventas en los Estados Unidos. Los alimentos procesados como pastas y otros alimentos producidos por la industria nacional, y los materiales textiles comerciados entre empresas de zonas francas, encabezan la lista de exportaciones hacia Haití. Las exportaciones hacia los Estados Unidos de alimentos frescos como frutas y vegetales y nuevas exportaciones de zonas francas también han contribuido.

Lo anterior no ha sido esencialmente la consecuencia de una estrategia de conquista de mercados alternativos y de promoción de nuevos productos de exportación sino más bien un resultado espontáneo de reorientación del comercio marcada por la pérdida de competitividad relativa de las confecciones textiles en los Estados Unidos y del "hallazgo" por parte de la industria manufacturera dominicana de un mercado de desahogo en Haití.

726 Ciencia y Sociedad 2014; 39(4): 703-730 
También de las preferencias arancelarias que Estados Unidos otorgó a Haití para las confecciones textiles que ha permitido que desde las zonas francas dominicanas se exporte material textil para su procesamiento ulterior en Haití, logrando articular una cadena productiva binacional.

Sin embargo, la política pública merece algún crédito por el dinamismo mostrado por las exportaciones de frutas y vegetales a los Estados Unidos, que también han contribuido a amortiguar el "golpe", porque el apoyo estatal, tangible e intangible, ha sido un factor relevante en ese desempeño.

Por último, algunas interrogantes claves quedan por responder. ¿Hasta dónde se sostendrá el crecimiento de las nuevas exportaciones de zonas francas? ¿Qué rol puede jugar la política pública y hacia dónde debe apuntar? ¿Constituye el mercado haitiano una promesa importante de auge exportador? ¿De qué dependería? ¿Cuánto podemos esperar de él para el desempeño exportador global? ¿Qué rol podrían jugar estas exportaciones agrícolas en la conformación de un nuevo perfil exportador? ¿Hasta dónde debe llegar el esfuerzo de impulso a las exportaciones agrícolas? ¿Hasta dónde puede llegar el sector manufacturero como actividad exportadora?

Estas preguntas pueden contribuir a ir perfilando una agenda de investigación aplicada que contribuya a la definición de una estrategia de reinserción económica internacional de República Dominicana. 


\section{Referencias bibliográficas ${ }^{4}$}

Balassa, B. (1965). Trade liberalization and revealed comparative advantage. The Manchester School of Economics and Social Science, 33, 99-123.

Dussel, E. (2001). Un análisis de la competitividad de las exportaciones de prendas de vestir de Centroamérica utilizando los programas y la metodología CAN y MAG. México: CEPAL-Serie Estudios y Perspectivas 1 .

Isa Contreras, P. (2013). Indicadores seleccionados del desempeño exportador de la República Dominicana: evaluación de una década. Ciencia y Sociedad, 38(1), 83-114.

\section{Base de datos consultada}

Datos procesados a partir de información estadística de International Trade Centre. Recuperado de www.trademap.org

4 Una aclaración necesaria: el trabajo realizado es muy empírico por lo que tiene solo dos referencias teóricas y que resultan ciertamente cruciales. 


\section{Bymairy de León}

Es economista (Summa Cum Laude), egresada del Instituto Tecnológico de Santo Domingo (INTEC). Durante sus años de estudios, fue miembro coordinadora del Seminario Permanente de Economía, Desarrollo y Ambiente de la Escuela de Economía y formó parte del equipo de investigación del Observatorio Dominicano de Comercio Internacional (ODCI). Actualmente se desempeña en el Viceministerio de Desarrollo Industrial, del Ministerio de Industria y Comercio (MIC) de la República Dominicana, como apoyo técnico en el desarrollo de estrategias que contribuyan a la investigación, innovación y desarrollo del sector industrial.

\section{Pável Isa Contreras}

Profesor del Instituto Tecnológico de Santo Domingo (INTEC), Área de Negocios. Coordina los trabajos de investigación del Observatorio Dominicano de Comercio Internacional (ODCI). Obtuvo el título de licenciado en Economía en el INTEC en 1988, el título de máster en Política Económica con especialidad en Economía Internacional por la Universidad Nacional de Costa Rica en 1994 y, el de doctorado en Economía por la Universidad de Massachusetts, Amherst, en 2003. Ha trabajado como investigador en el CIECA, que es un grupo de reflexión económica de la República Dominicana, y como director de Investigación de CRIES, una red regional de América Latina y el Caribe para la investigación social y 
económica. Fue asesor económico del Ministerio de Hacienda y del Ministerio de Economía, Planificación y Desarrollo de República Dominicana. Su trabajo académico se ha concentrado en temas de comercio internacional, política comercial, desarrollo humano, política social y desarrollo territorial. También se ha desempeñado como profesor en varias universidades del país y del exterior.

Email: pavel.isa@intec.edu.do

\section{Virginia Melo}

Es egresada de la carrera de Economía del Instituto Tecnológico de Santo Domingo (INTEC), institución en la que completó sus estudios de grado con honores (Summa Cum Laude). Trabajó como asistente de Investigación para el Observatorio Dominicano de Comercio Internacional (ODCI) entre marzo de 2012 y junio de 2013. Actualmente labora en la Oficina Nacional de Estadística (ONE) de la República Dominicana y en la División de Investigaciones como analista.

También se desempeña en investigaciones de corte económico, social, demográfico y de género, de alto impacto nacional.

Recibido: 04/10/2014 Aprobado: 09/11/2014 